\title{
Release of Three Iceberg Lettuce Populations with Combined Resistance to Two Soilborne Diseases
}

\author{
Ryan J. Hayes ${ }^{1}$ \\ United States Department of Agriculture, Agricultural Research Service, \\ Crop Improvement and Protection Unit, 1636 E. Alisal Street, Salinas, CA \\ 93905
}

\author{
German Sandoya ${ }^{2}$ \\ Genome Center and Department of Plant Sciences, University of California, \\ Davis, CA 95616
}

\author{
Beiquan Mou and Ivan Simko ${ }^{3}$ \\ United States Department of Agriculture, Agricultural Research Service, \\ Crop Improvement and Protection Unit, 1636 E. Alisal Street, Salinas, CA \\ 93905

\section{Krishna V. Subbarao \\ Department of Plant Pathology, University of California, Davis, c/o U.S. Agricultural Research Station, 1636 E. Alisal Street, Salinas, CA 93905}

Additional index words. disease resistance, breeding, genetics, distributive breeding, verticillium wilt, corky root

The Agricultural Research Service, United States Department of Agriculture, and the University of California, Davis, announce the release of three $F_{2: 4}$ breeding populations of iceberg lettuce (Lactuca sativa $\mathrm{L}$.). The breeding populations, designated RH14-1156, RH14-1157, and RH14-1158, are the first to combine resistance to the soilborne diseases corky root and verticillium wilt race 1 . The populations are genetically fixed for disease resistance, and all progeny descending from these populations are expected to be resistant. These populations should be used to select inbred iceberg lettuce cultivars adapted to environments where corky root and verticillium wilt race 1 are prevalent and damaging.

Corky root and verticillium wilt are prevalent soilborne diseases that constrain commercial lettuce production in coastal California. Corky root is a deterioration of the root system that leads to reduced head size, resulting in heads that are less marketable. Bacteria from several

\footnotetext{
Received for publication 6 Oct. 2017. Accepted for publication 5 Dec. 2017.

This research was supported by the California Leafy Greens Research Program.

We thank Bengard Farms for providing field space to conduct experiments.

${ }^{1}$ Current address: United States Department of Agriculture, Agricultural Research Service, Forage Seed and Cereal Research Unit, 3450 SW Campus Way, Corvallis, OR 97321.

${ }^{2}$ Current address: Everglades Research \& Education Center, University of Florida, 3200 E Palm Beach Road, Belle Glade, FL 33430.

${ }^{3}$ Corresponding author. E-mail: ivan.simko@ars. usda.gov.
}

genera in the Sphingomonadaceae family can cause the disease (van Bruggen et al., 2014). The recessive gene cor confers partial or incomplete resistance to many pathogenic isolates causing corky root (Brown and Michelmore, 1988; Mou and Bull, 2004; van Bruggen et al., 2014). Verticillium wilt is a destructive disease found on the central coast of California incited by the soil-dwelling fungus Verticillium dahliae Kleb (Atallah et al., 2011). The fungus infects the plant's roots and colonizes the vascular tissue, resulting in discoloration or darkening of vascular tissue, leaf wilting, plant collapse, and ultimately death. Two pathogenic races (race 1 and race 2) of $V$. dahliae on lettuce are known (Vallad et al., 2006). Resistance to race 1 is conferred by the dominant Verticillium resistance 1 ( Vrl) (Hayes et al., 2011; Sandoya et al., 2017). Race 1 isolates currently predominate in commercial lettuce fields in coastal California, and $V r l$ provides effective control in field sites where the gene has been tested (Gurung et al., 2014; Hayes et al., 2007).

Selection for resistance to soilborne root diseases can be difficult and labor intensive. Molecular markers can be used, but are not always cost effective or available for smaller lettuce breeding programs. An alternative is for public breeding programs to develop germplasm genetically uniform for disease resistance, but genetically variable for horticultural, agronomic, and quality traits (Hayes et al., 2014). External breeding programs could then select within these populations to develop new and unique cultivars without the need to evaluate for disease resistance. Here, we report the development and release of three early generation iceberg breeding populations that are the first to combine resistances to verticillium wilt and corky root.

\section{Origin and Development}

The $F_{2: 4}\left(F_{2}\right.$ derived $\left.F_{4}\right)$ breeding populations are derived from a cross between the breeding line RH09-0689 and 'Telluride'. The full pedigree of these breeding lines is shown in Fig. 1. 'Telluride' is a commercially available (Plant Variety Protection certificate number 200300168) iceberg cultivar developed by the seed company Enza Zaden with the cor gene. 'Telluride' is cataloged as PI 632993 in the National Plant Germplasm System (https://npgsweb.ars-grin.gov/gringlobal/accessiondetail.aspx?id=1644842). The United States Department of Agriculture (USDA) $F_{3: 4}$ iceberg breeding line RH090689 was the source of $V r l$, which was originally introgressed from 'La Brillante'. In addition to 'La Brillante', RH09-0689 has the USDA cultivars Tiber and Pacific in its pedigree. 'Tiber' and 'Pacific' are both susceptible to corky root and verticillium wilt. A descendant from RH09-0689 was released in 2015 as RH12-3195, and is available at the National Plant Germplasm System as PI 673091 (https:// npgsweb.ars-grin.gov/gringlobal/accessiondetail. aspx?id=1921390). The sibling line RH12-3197 was used as a control in several experiments during field-testing of these populations. Other control cultivars used in field experiments include the iceberg 'Salinas', which is susceptible to verticillium wilt and corky root, and iceberg cultivars with the cor gene including 'Durango', 'Hallmark', 'Glacier', 'Quest MT', and 'Sniper'.

Lettuce is a naturally self-pollinating species that does not suffer from inbreeding depression, and a combination of the pedigree and bulk breeding methods were used to develop RH14-1156, RH14-1157, and RH141158 . Forty-five $F_{2: 3}$ families were developed by growing $F_{2}$ plants in a nondisease-infested field site in Salinas, CA, selecting plants for iceberg type horticultural characters and allowing the selected plants to flower and self-pollinate. The resulting $F_{2 \cdot 3}$ families were evaluated in a May-planted field experiment conducted in a USDA, Salinas field site, artificially infested with $V$. dahliae race 1 isolate VdLs16. This field site is also naturally infested with corky root. Each family was replicated three times and planted with the checks RH12-3195, 'Telluride', and 'Durango'. In mid-July, plants were visually evaluated for foliar wilting typical of verticillium wilt. Thirtyfour families were identified as verticillium wilt-susceptible or likely segregating for resistance and were discarded. All plants $(\approx 90)$ of the eleven remaining families and checks were uprooted, split longitudinally, and evaluated for internal root discoloration typical of verticillium wilt, using the method of Hayes et al. (2011). A preliminary assessment of corky root resistance was also conducted by recording the family numbers of families that had a low incidence of plants with severely symptomatic roots. Internal root discoloration in these families ranged from $0 \%$ to $6 \%$ and was $1 \%$ in RH12-3195. 'Telluride' and 'Durango' had 65\% 


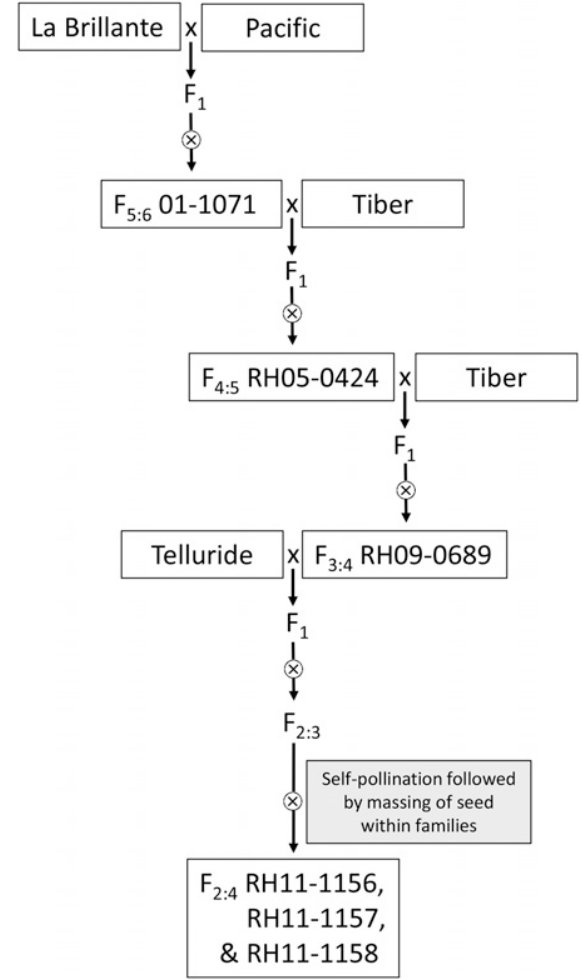

Fig. 1. Pedigree of iceberg breeding lines RH111156, RH11-1157, and RH11-1158 with combined resistance to verticillium wilt and corky root disease. Seeds from each generation of self-pollination were kept separate to develop $F_{5: 6}$ 01-1071, $F_{4: 5}$ RH05-0424, and $F_{3: 4}$ RH090689 . Seeds from self-pollination of $\approx 90 F_{2: 3}$ plants within three families derived from Telluride $\times$ RH09-0689 were massed to create three $F_{2: 4}$ seed lots.

and $56 \%$ incidence of root discoloration, respectively. Families segregating for $\mathrm{Vrl}$ would be expected to have a disease incidence of $25 \%$, although this could be lower because of the occurrence of disease escapes. Vascular discoloration in $6 \%$ or less of tested plants indicates that the eleven families are genetically uniform for verticillium wilt resistance. Preliminary assessment of corky root resistance identified three of the eleven families with resistance as good as or better than 'Telluride' and 'Durango'. RH12-3195 was highly susceptible to corky root.

The following season, the three selected $F_{2: 3}$ families combining verticillium wilt and corky root resistance were evaluated in the same field site. Three replications were used for each entry in a randomized complete block design (RCBD) and included 'Telluride', RH12-3197, 'Quest MT', and 'Salinas'. The experiment was planted in April and evaluated in June. All plants $(\approx 90$ per entry) were evaluated for verticillium wilt disease incidence and corky root severity using a 0 to 9 scale reported in Brown and Michelmore (1988). Verticillium wilt disease incidence in 'Salinas', 'Quest MT', and 'Telluride' ranged from $88 \%$ to $90 \%$. RH12-3197 and the $F_{2: 3}$ families had $<3 \%$ symptomatic plants, which was significantly lower $(P<0.01)$ than the control cultivars. 'Salinas' and RH12-3197 had corky root severity means greater than 7.8, which was significantly higher than 'Quest MT' (corky severity mean $=6.2$ ) and 'Telluride' (corky severity mean $=6.4$ ). The three $F_{2: 3}$ families had corky root severity means less than 5.9. This was significantly lower than all other entries, with the exception that 'Quest MT' was not significantly different from one $F_{2: 3}$ family. More than 90 plants from each of the three $F_{2: 3}$ families were greenhouse grown and allowed to self-pollinate. Seeds from each plant were massed to create three $F_{2: 4}$ families designated RH14-1156, RH141157, and RH14-1158.

\section{Horticultural Characters and Corky Root Resistance}

RH14-1156, RH14-1157, and RH14-1158 were planted in three field experiments. These included two USDA, Salinas sites that were naturally infested with corky root (SP15-4 and FA15-1) and the third, a growercooperator site near Salinas, CA (experiment VT15-3, Table 1), that was reportedly infested with verticillium wilt (Table 1). However, neither verticillium wilt nor corky root disease occurred in VT15-3 and no disease data were collected. All experiments were an RCBD with three replications and included the parents and control cultivars Glacier, Hallmark, Sniper, Telluride, and RH12-3197. Planting dates were June, July, and August, resulting in evaluations in August, September, and October. More than 20 heads from each plot were individually assessed for corky root severity, head firmness, head weight, head diameter, head height, core height, and the occurrence of the physiological defect, tipburn in FA15-1 and VT15-3. Only corky root resistance and core height were measured in SP15-4. Data were analyzed using Proc Mixed in SAS (Version 9.2; SAS Institute, Inc., Cary, NC). Tipburn occurrence was used to calculate the percentage of plants with tipburn in each plot, which was square root then arcsin transformed before analysis Downy mildew (incited by Bremia lactucae) naturally occurred in FA15-1 and disease severity was evaluated using the method of Simko et al. (2013). Within line (plant-toplant) variances were calculated for all traits except tipburn for each breeding population, breeding line, or cultivar. The variances for the breeding lines and cultivars were further pooled into a single variance estimate. $\mathrm{Be}$ cause cultivars and breeding lines are inbred and homozygous, the pooled variance is an estimate of environmental variation. An $F$-test between the breeding population and environmental variances was conducted to test for plant-to-plant genetic variation within a breeding population.

The corky root severity means of RH141156, RH14-1157, and RH14-1158 were similar to the corky root-resistant cultivars Glacier, Hallmark, Sniper, and Telluride (Table 1). Means of the breeding populations were always significantly lower than the susceptible control 'Salinas'. RH14-1156,
RH14-1157, and RH14-1158 had significantly lower corky root severity means compared with RH12-3197 in FA15-1, but not in field experiment SP15-4 (Table 1). RH14-1156, RH14-1157, and RH14-1158 expressed downy mildew susceptibility that was similar to 'Salinas', 'Glacier', and 'Telluride' (data not shown).

The breeding populations were similar to the parent and control cultivars for head firmness and head diameter (Table 1). The incidence of the physiological defect, tipburn, was variable across entries and locations. RH14-1157 had the lowest incidence in both experiments, although no cultivars or breeding populations were significantly different from each other. RH14-1157 had the highest head weight in both field experiments and was significantly greater than RH111156, 'Telluride', 'Glacier', and 'Salinas' in field experiment VT15-3 (Table 1). None of the head weight means in the FA15-1 experiment were significantly different. Head height and core height exhibited significant differences among breeding populations and cultivars. RH12-3197 and 'Glacier' had the shortest heads (lowest head height), whereas the breeding populations were similar to 'Salinas' and 'Telluride'. RH14-1157 and RH12-3197 generally had the shortest cores, whereas RH14-1158 had the tallest. Significant plant-to-plant genetic variation within breeding populations was commonly detected for core length, particularly in breeding population RH14-1158 (Table 2). RH141157 exhibited significant genetic variation for head weight in both field experiments. Significant variation was intermittently detected across locations and breeding populations for head firmness and head height. Within breeding population variances for corky root disease severity were similar to the environmental variance, indicating that these populations do not segregate for corky root resistance.

\section{Description, Use, and Availability}

Breeding populations RH14-1156, RH141157, and RH14-1158 are iceberg germplasm that is genetically uniform for resistance to corky root and verticillium wilt. Horticultural characters of these populations are generally similar to modern iceberg cultivars. In limited testing, RH14-1157 appeared to have an improved combination of higher head weight and shorter cores compared with the cultivars tested in these experiments. RH14-1158 contains genotypes that are susceptible to premature bolting.

This germplasm is being released as $F_{2: 4}$ populations. Randomly selected $F_{2}$ plants are expected to be heterozygous for $50 \%$ of the loci where the parents have different alleles. Seed increase without selection will maintain this variation, although the frequency of homozygous loci in individual plants will increase after self-pollination. Although these populations were selected for horticultural characters in the $F_{2}$ generation and for resistance in subsequent generations, it is likely that these populations have sufficient 
Table 1. Performance of three $F_{2: 4}$ iceberg breeding populations, parents, and control cultivars for disease and horticultural traits in three replicated field experiments in Salinas, CA.

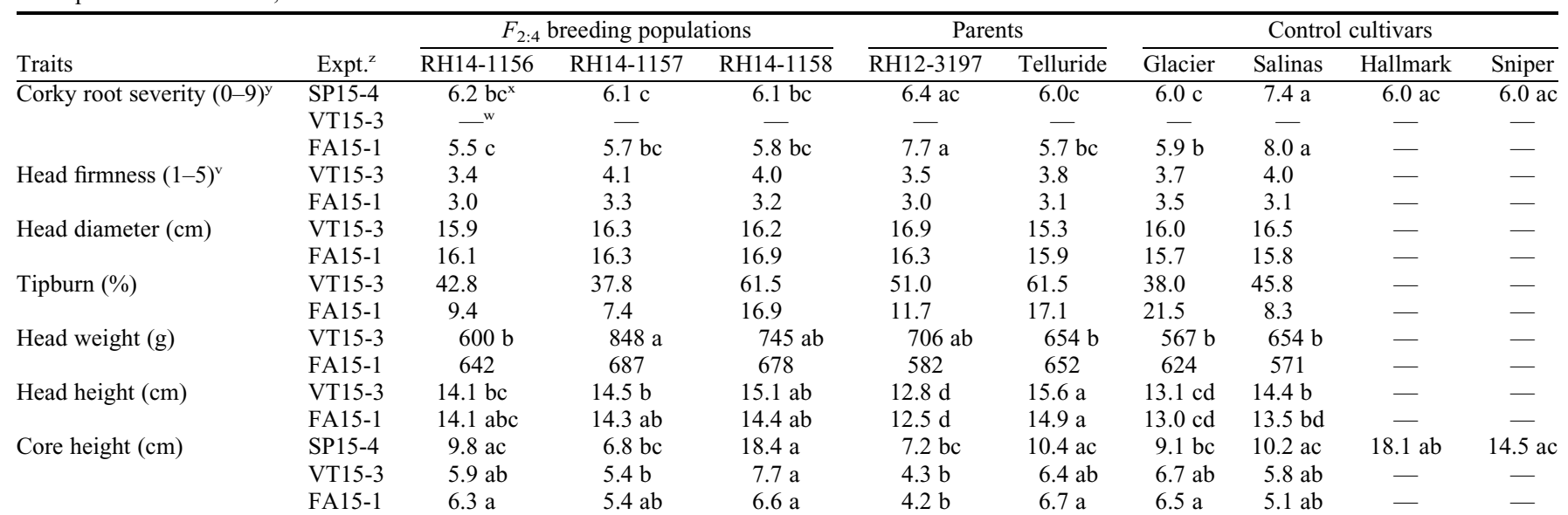

${ }^{\mathrm{z}}$ Experiments conducted at the USDA Spence Farm (SP15-4), grower-cooperator field site (VT15-3), and the USDA Field-A site (FA15-1). Harvest dates were on Aug. 28, Sept. 10, and Oct. 21, respectively.

${ }^{\mathrm{y}}$ Corky root disease severity rated as $0=$ no disease to $9=$ severe disease causing plant death according to the scale reported by Brown and Michelmore (1988).

${ }^{x}$ Means followed by different letters are significantly different at $P<0.01$ using Tukey's multiple comparison procedure.

wDash (-) indicates no data were collected. Corky root disease did not occur in VT15-3. 'Hallmark' and 'Sniper' were not planted in VT15-3 and FA15-1.

${ }^{\mathrm{v}}$ Head firmness rated as 1 for soft and immature to 5 for splitting and over mature. Optimal firmness or peak maturity is 3 or 4 .

Table 2. Variance between plants for three $F_{2: 4}$ iceberg breeding populations and environmental variation for horticultural and disease traits in three replicated field experiments in Salinas, CA.

\begin{tabular}{|c|c|c|c|c|c|}
\hline \multirow[b]{2}{*}{ Traits } & \multirow[b]{2}{*}{ Expt. ${ }^{z}$} & \multicolumn{4}{|c|}{ Between plant variance } \\
\hline & & RH14-1156 & RH14-1157 & RH14-1158 & Environment ${ }^{y}$ \\
\hline Corky root severity $(0-9)^{x}$ & VT15-3 & - $w$ & - & - & - \\
\hline \multirow[t]{2}{*}{ Head firmness $(1-5)^{\mathrm{v}}$} & VT15-3 & $1.05^{*}$ & 0.95 & 0.81 & 0.96 \\
\hline & FA15-1 & 0.36 & 0.32 & 0.20 & 0.26 \\
\hline \multirow[t]{2}{*}{ Head diameter $(\mathrm{cm})$} & VT15-3 & 2.51 & 3.41 & 2.92 & 3.54 \\
\hline & FA15-1 & 3.35 & 4.35 & 4.96 & 4.08 \\
\hline \multirow[t]{2}{*}{ Head height $(\mathrm{cm})$} & VT15-3 & $2.07 *$ & 1.70 & 1.71 & 1.28 \\
\hline & FA15-1 & 1.28 & 1.26 & $2.18^{*}$ & 1.25 \\
\hline \multirow[t]{3}{*}{ Core height $(\mathrm{cm})$} & SP15-4 & 29.09 & 6.00 & $86.22 * *$ & 23.43 \\
\hline & VT15-3 & $2.90 *$ & $2.46^{*}$ & $10.53^{* *}$ & 1.85 \\
\hline & FA15-1 & $4.74 *$ & 2.75 & $8.13^{* *}$ & 3.22 \\
\hline
\end{tabular}

${ }^{\mathrm{z}}$ Experiments conducted at the USDA Spence Farm (SP15-4), grower-cooperator field site (VT15-3), and the USDA Field-A site (FA15-1). Harvest dates were on Aug. 28, Sept. 10, and Oct. 21, respectively.

${ }^{\mathrm{y}}$ The environmental variance was calculated as the variance between plants within cultivars, which was then pooled across cultivars.

${ }^{\mathrm{x}}$ Corky root disease severity rated as $0=$ no disease to $9=$ severe disease causing plant death according to the scale reported by Brown and Michelmore (1988).

${ }^{\mathrm{w}}$ Dash (-) indicates no data were collected. Corky root disease did not occur in VT15-3.

${ }^{v}$ Head firmness rated as 1 for soft and immature to 5 for splitting and over mature.

*,**Between plant variance within breeding population significantly greater than the environmental variance at $P<0.05$ or $P<0.01$ using an $F$-test.

genetic variation to enable further performance improvements or development of unique inbred lines. Lettuce breeders should use these populations to select plants and eventual inbred lines for adaptation to environments where corky root and verticillium wilt are prevalent problems. The resulting inbred lines selected from these populations are expected to be resistant to both diseases.

Limited seed samples of these breeding populations are available for distribution to all interested parties for research purposes. RH14-1156, RH14-1157, and RH14-1158 are being publically released with no intellectual property protection for the development and commercialization of new cultivars by seed companies, universities, nongovernmental organizations, or other bona fide private or public research organizations. It is requested that appropriate recognition be made if these populations contribute to research or the development of new germplasm, breeding lines, or cultivars. Written requests for seed can be sent to Ivan Simko, USDA-ARS, 1636 E. Alisal St., Salinas, CA 93905 or sent through e-mail (ivan.simko@ars. usda.gov).

\section{Literature Cited}

Atallah, Z.K., R.J. Hayes, and K.V. Subbarao. 2011. Fifteen years of verticillium wilt of lettuce in America's salad bowl: A tale of immigration, subjugation, and abatement. Plant Dis. 95:784-792.
Brown, P.R. and R.W. Michelmore. 1988. The genetics of corky root resistance in lettuce. Phytopathology 78:1145-1150.

Gurung, S., D.P.G. Short, Z.K. Atallah, and K.V. Subbarao. 2014. Clonal expansion of Verticillium dahliae in lettuce. Phytopathology 104:641-649.

Hayes, R.J., G.E. Vallad, Q-M. Qin, R.C. Grube, and K.V. Subbarao. 2007. Variation for resistance to verticillium wilt in lettuce (Lactuca sativa L.). Plant Dis. 91:439-445.

Hayes, R.J., L.K. McHale, G.E. Vallad, M.J. Truco, R.W. Michelmore, S.J. Klosterman, K. Maruthachalam, and K.V. Subbarao. 2011. The inheritance of resistance to verticillium wilt caused by race 1 isolates of Verticillium dahliae in the lettuce cultivar la brillante. Theor. Appl. Genet. 123:509-517.

Hayes, R.J., M.A. Trent, B. Mou, I. Simko, S.J. Gebben, and C.T. Bull. 2014. Baby leaf lettuce 
germplasm enhancement: Developing diverse populations with resistance to bacterial leaf spot caused by Xanthomonas campestris pv. vitians. HortScience 49:18-24.

Mou, B. and C. Bull. 2004. Screening lettuce germplasm for new sources of resistance to corky root. J. Amer. Soc. Hort. Sci. 129:712716.

Sandoya, G.V., S. Gurung, D.P. Short, K.V. Subbarao, R.W. Michelmore, and R.J. Hayes. 2017. Genetics of resistance in lettuce to races 1 and 2 of Verticillium dahliae from different host species. Euphytica 213:20.

Simko, I., A.J. Atallah, O.E. Ochoa, R. Antonise, C.H. Galeano, M.J. Truco, and R.W. Michelmore. 2013. Identification of QTLs conferring resistance to downy mildew in legacy cultivars of lettuce. Sci. Rpt. 3:2875.

Vallad, G.E., Q-M. Qin, R.C. Grube, R.J. Hayes, and K.V. Subbarao. 2006. Characterization of race-specific interaction among isolates of Verticillium dahliae pathogenic on lettuce. Phytopathology 96:1380-1387.

van Bruggen, A.H.C., O. Ochoa, I.M. Francis, and R.W. Michelmore. 2014. Differential interactions between strains of Rhizorhapis, Sphingobium, Sphingopyxis or Rhizorhabdus and accessions of Lactuca spp. with respect to severity of corky root disease. Plant Pathol. 63:1053-1061. 